\title{
Gönen deltası kumul bitki çeşitliliği, tehdit faktörleri ve çözüm önerileri
}

\section{Dune plant diversity of Gönen delta, threat factors and solution suggestions}

\author{
Fatih SATIL ${ }^{1(\mathbb{D})}$, Gülendam TÜMEN ${ }^{1}(\mathbb{D})$, Selami SELVi ${ }^{2}$ \\ ${ }^{1}$ Balıkesir Üniversitesi, Fen-Edebiyat Fakültesi, Biyoloji Bölümü, Çağış Kampüsü, Balıkesir, Türkiye \\ ${ }^{2}$ Balıkesir Üniversitesi, Altınoluk MYO, Bitkisel ve Hayvansal Üretim Bölümü, Edremit, Balıkesir, Türkiye
}

\section{Eser Bilgisi / Article Info}

Araştırma makalesi / Research article DOI: 10.17474/artvinofd.517291

\begin{tabular}{l}
\hline Sorumlu yazar / Corresponding author \\
Selami SELVi \\
e-mail: sselvi2000@yahoo.com \\
\hline Geliş tarihi / Received \\
24.01 .2019 \\
Düzeltme tarihi / Received in revised form \\
23.09.2019 \\
Kabul Tarihi / Accepted \\
30.09.2019 \\
Elektronik erişim / Online available \\
30.10.2019
\end{tabular}

\section{Anahtar kelimeler:}

Balıkesir

Biyoçeşitlilik

Ekoloji

Flora

Gönen

Kumul

\section{Keywords:}

Balıkesir

Biodiversity

Ecology

Flora

Gönen

Dune

\begin{abstract}
Özet
Bu çalışmanın amacı, Gönen deltasındaki kıyı kumul bitkilerini ve bu alanlardaki çevre sorunlarını tespit etmektir. Ayrıca, kumul alanlardaki bitki çeşitliliğini tehdit eden faktörlere çözüm önerileri sunmaktır. Floristik çalışmalar sonucunda alanda; 32 familyaya ait 81 cins ve 89 takson tespit edilmiştir. Bölgedeki kumul alanların karakteristik florasında Asteraceae, Brassicaceae, Amaranthaceae ve Apiaceae familyaları ağırlıktadır. Cakile maritima, Kali turgida ve Atriplex portulacoides neredeyse bütün araştırma alanlarına yayılmış durumdadırlar. Sahada yapılan floristik ve ekolojik gözlemler sonucunda, kumul türlerin yayılış alanlarındaki tehdit faktörleri belirlenmiştir. Sanayi ve kanalizasyon sularının arıtılmadan akarsu ve denize akıtılması, tarımsal faaliyetler ve kıyılardan kum alımı gibi çeşitli nedenler kumul alanların hızla kirlenmesine yol açmaktadır. Bölgedeki dericilik sektörü su kaynaklarına ve kumul alanlara en önemli zararı veren faaliyetlerdendir. Kumul bitki türlerinden özellikle Pancratium maritimum soğanlarının halk tarafından toplanıyor olması ve yayılış alanındaki habitat bozulmaları bu türün popülasyonlarını oldukça düşürmüştür. Bölgedeki ekolojik sorunların temelinde denetimsizlik ve bilinçsizlik yer almaktadır. Bu nedenle, ekolojik planlama sürecinde sanayicilerin ve bölge halkının da bilinçlendirilmesi önemlidir.
\end{abstract}

\begin{abstract}
The aim of this study is to determine coastal dune plants in Gönen delta and environmental problems in these areas. In addition, it offers solutions to the factors that threaten plant diversity in dune areas. As a result of floristic studies were determined 81 genera and 89 taxa belonging to 32 families. Asteraceae, Brassicaceae, Amaranthaceae and Apiaceae families are predominant in the flora of the region. Cakile maritima, Kali turgida and Atriplex portulacoides are spread over almost all research areas. As a result of floristic and ecological observations conducted in the field, the threat factors in the distribution areas of the dune species were determined. Various reasons as drained into river and sea without the purified of industrial and sewage waters, agricultural activities and carried of sand from the coasts lead to rapid pollution of the dune areas. The leather industry in the region is one of the most important damages to the water resources and dune areas. Bulbs of Pancratium maritimum gathered from local people and the habitat disturbances in the distribution area, this species populations were greatly reduced. Ecological problems in the region are based on uncontrollability and unconsciousness. Therefore, it is important to raise awareness of industrialists and local people in the ecological planning process.
\end{abstract}

\section{GiRiş}

Sulak alanlar, yeryüzünün en zengin ve en üretken ekosistemlerini oluşturmaktadır. Bu alanlar yöre insanlarına ve ülkenin geneline geniş yelpazede hizmet veren oldukça karmaşık doğal sistemlerdir ve yeryüzündeki başka hiçbir ekosistemle karşılaştırılmayacak ölçüde işlev ve değerlere sahiptir (Tirıl, 2006).

Gönen Çayı Deltası, Marmara Denizi'nin güneyinde, Marmara Bölgesi'nin Güney Marmara Bölümü sınırları içerisinde yer almaktadır. Gönen havzası sınırındaki boğazdan (Gönen Çayı güney boğazı) giriş yapan Gönen Çayı, aynı ad ile anılan alüvyal taşkın ovasını oluşturup Gönen Çayı kuzey boğazı vasıtasıyla Gönen Çayı deltasını yaparak Marmara Denizine dökülmektedir (Özşahin, 2013).

Gönen Çayı Deltası her ne kadar Ramsar Alanı kapsamında değilse de ülkemizin önemli sulak alanlarından birisidir. Gönen Çayı Deltası Sulak Alanı, üreyen küçük karabatak, kışlayan tepeli pelikan türleri ile Uluslararası Öneme Sahip Sulan Alan Listesine aday olabilecek bir sulak alandır. 
Erinç'e göre (2001); Türkiye'nin kıyı kumulları 75 farklı alanda gözlenmektedir. Bu kıyı kumullarından 8' i Balıkesir ili sınırlarında yer almaktadır (Çizelge 1).

\begin{tabular}{|c|c|c|c|}
\hline No & il & İlçe & Kumul alan ismi \\
\hline 1 & \multirow{8}{*}{ Balıkesir } & Ayvalık & Altınova \\
\hline 2 & & & Sarımsaklı \\
\hline 3 & & & Yumra Burnu \\
\hline 4 & & Burhaniye & Armutova \\
\hline 5 & & Edremit & Çoruk \\
\hline 6 & & Erdek & Belkıs tombolosu \\
\hline 7 & & Gönen & Gönen deltası \\
\hline 8 & & & Karabiga Deltası \\
\hline
\end{tabular}

Türkiye'nin kıyı kumulları floristik bakımdan oldukça çeşitlidir. Bu kumulların 15 tanesi önemli bitki alanı olarak tanımlanmıştır. Önemli bitki alanlarında yaklaşık 100 kadar endemik bitki yer alır. Yine bu sahalarda yayılış alanı bulan bitkilerden bazıları Ulusal, Avrupa ve Küresel ölçekte nesli tehlike altında kabul edilen türlerdir (Avcı ve ark. 2015; Avcı 2017a).

Balıkesir ve çevresinde birçok floristik çalışmalar olmasına rağmen çalışma bölgesinde Kapıdağ Yarımadası florası (Öner ve Akbin 2010) ile Kuş Cenneti ve çevresinin florası (Tümen ve ark. 2018) üzerinde yapılmış çalışmalar dışında bir çalışmaya rastlanmamıştır. Şimdiye kadar Gönen Deltası kumul bitkileri üzerine yapılmış bir çalışma bulunmamaktadır. Bu çalışmada, Gönen kıyı kumulundaki bitki çeşitliliği tespit edilmiş, kumulları ve bitkileri tehdit eden faktörler ortaya konmuş ve çözüm önerileri getirilmiştir

\section{MATERYAL ve YÖNTEM}

Çalışma, Gönen deltası kıyı kumul alanlarında gerçekleştirilmiştir. Alanın coğrafik haritası Şekil 1' de gösterilmiştir.

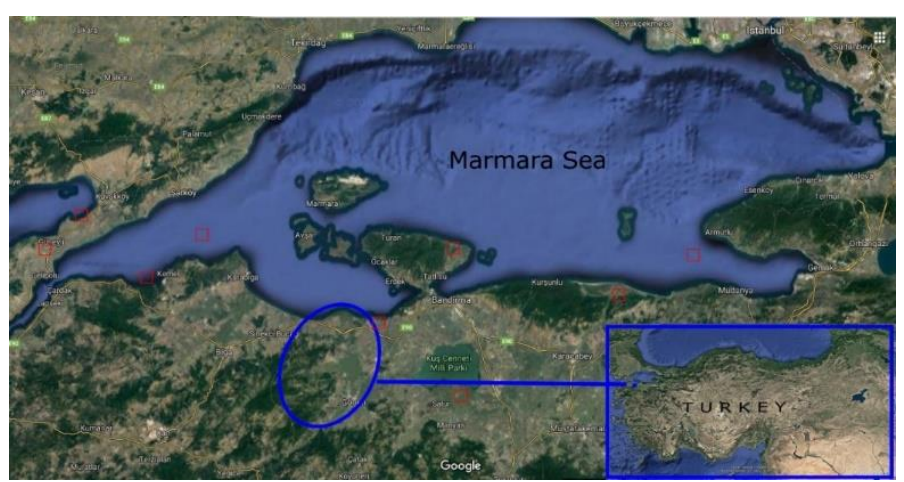

Şekil 1. Gönen Deltası

2016-2017 yılları arasında gerçekleştirilen bu çalışmada, alanda dört mevsim floristik ve ekolojik gözlemler yapılarak bitki çeşitliliği ve çevre sorunları tespit edilmiştir. Floristik çalışmalarda, alandaki kumul ve tuzcul bitki türleri toplanmış ve herbaryum materyalleri haline getirilmişlerdir. Toplanan bitkilerin teşhisi için temel kaynak olarak başta "Flora of Turkey" olmak üzere "Mountain Flora of Greece", "Flora of Europae" ve bölgede yapılan floristik çalışmalardan faydalanılmıştır (Davis 1965-1985; Davis ve ark., 1988; Güner ve ark., 2001; Strid ve Tan 1991; Tutin ve ark., 1964-1980; Güner ve ark. 2012). Teşhisi yapılan herbaryum örnekleri Balıkesir Üniversitesi Altınoluk Meslek Yüksekokulu Botanik Laboratuvarı' nda saklanmaktadır. Gönen deltasında tespit edilen taksonların türkçe isimleri Güner ve ark. (2012)' a göre, güncel bilimsel isimleri Catalogue of Life" a (Roskov ve ark. 2019) ve taksonların tehlike kategorileri ise IUCN (2019)' a göre Çizelge 2'de sunulmuştur.

\section{BULGULAR VE TARTIŞMA}

Floristik çalışmalar sonucunda alanda; 32 familyaya ait 81 cins ve 89 takson tespit edilmiştir. Bölgedeki kumul alanların karakteristik florasında Asteraceae, Brassicaceae, Amaranthaceae ve Apiaceae familyaları ağırlıktadır. Bu taksonların 27' sinin (\%30) LC (Düşük Riskli) tehlike kategorisinde yer aldığı görülmüştür (Çizelge 2). 
Çizelge 2. Gönen Deltasında tespit edilen kumul bitki florası

\begin{tabular}{|c|c|c|c|c|c|}
\hline Familya & Bilimsel İsim & Türkçe İsim & $\begin{array}{l}\text { Fitocoğrafik } \\
\text { Elementi }\end{array}$ & $\begin{array}{l}\text { Tehlike Kategorisi } \\
\text { (IUCN' e göre) }\end{array}$ & $\begin{array}{l}\text { Lokalite ve toplayıcı numaraları } \\
\text { (A1(A) Balıkesir: Gönen Deltası }\end{array}$ \\
\hline Amaranthaceae & Beta maritima $\mathrm{L}$. & Kıyıpancarı & - & - & $\begin{array}{l}\text { Deniz kıyıs, kumullar, } 40^{\circ} 18^{\prime} 16.72 " \mathrm{~K} \\
27^{\circ} 33^{\prime} 52.38^{\prime \prime} \mathrm{D}, 7.04 .2017,1 \mathrm{~m}, \mathrm{SV} 2031\end{array}$ \\
\hline Amaranthaceae & Atriplex portulacoides $\mathrm{L}$. & Kocabetne & - & - & $\begin{array}{l}\text { Deniz kıyısı, kumullar, } 40^{\circ} 19^{\prime} 7.31^{\prime \prime K}, 27^{\circ} 35^{\prime} 47.32^{\prime \prime D} \text {, } \\
12.03 .2017,1 \mathrm{~m} \text {, SV } 2001\end{array}$ \\
\hline Amaranthaceae & Chenopodiastrum murale (L.) S. Fuentes, Uotila \& Borsch & Salmanca & - & - & $\begin{array}{l}\text { Deniz kıyısI, 40¹9'3.92"K, } 27^{\circ} 38^{\prime} 40.66 " \mathrm{D} \\
15.03 .2017,1 \mathrm{~m} \text {, SV } 2011\end{array}$ \\
\hline Amaranthaceae & Kali turgida (Dumort.) Gutermann & Döngele & - & - & $\begin{array}{l}\text { Deniz kııısı, kumullar, } 40^{\circ} 18^{\prime} 56.40^{\prime \prime K} \\
27^{\circ} 35^{\prime} 30.58^{\prime \prime} \mathrm{D}, 25.05 .2018,1 \mathrm{~m} \text {, SV } 2360\end{array}$ \\
\hline Amaranthaceae & Salsola soda L. & Deniz fasülyesi & - & - & $\begin{array}{l}\text { Deniz kıyısı, kumullar, } 40^{\circ} 19^{\prime} 27.88^{\prime \prime K} \\
27^{\circ} 37^{\prime} 23.41 " \mathrm{D}, 25.05 .2018,1 \mathrm{~m} \text {, SV } 2361\end{array}$ \\
\hline Amaranthaceae & Suaeda prostrata Pall. & Yatıkcirim & - & - & $\begin{array}{l}\text { Deniz kııısı, kumullar, 40¹8'36.60"K, } \\
27^{\circ} 34^{\prime} 45.69 " \mathrm{D}, 1 \mathrm{~m}, 12.03 .2017 \text {, SV } 2003\end{array}$ \\
\hline Amaryllidaceae & Allium commutatum Guss. & Itdirseği & Akdeniz & LC & $\begin{array}{l}\text { Deniz kııısı, kumullar, } 40^{\circ} 18^{\prime} 13.03 " \mathrm{~K} \\
27^{\circ} 33^{\prime} 45.64 " \mathrm{D}, 1 \mathrm{~m}, 12.03 .2017 \text {, SV } 2004\end{array}$ \\
\hline Amaryllidaceae & Allium roseum $\mathrm{L}$. & Gülsoğanı & Akdeniz & LC & $\begin{array}{l}\text { Deniz kıyısının bitimi, 40¹6'53.53"K, } \\
27^{\circ} 32^{\prime} 27.62^{\prime \prime D}, 47 \mathrm{~m}, 15.03 .2017 \text {, sV } 2014\end{array}$ \\
\hline Amaryllidaceae & Narcissus tazetta L. & Nergis & - & - & $\begin{array}{l}\text { Deniz kıyısının bitimi, } 40^{\circ} 17^{\prime} 34.25^{\prime \prime K}, 27^{\circ} 29^{\prime} 5.17^{\prime \prime D} \text {, } \\
19 \mathrm{~m}, 7.04 .2017 \text {, SV } 2033\end{array}$ \\
\hline Amaryllidaceae & Pancratium maritimum L. & Kumzambağı & - & LC & $\begin{array}{l}\text { Deniz kıyısının bitimi, } 40^{\circ} 18^{\prime} 4.46^{\prime \prime K}, 27^{\circ} 27^{\prime} 40.25^{\prime \prime} \mathrm{D}, \\
4 \mathrm{~m}, 04.04 .2018 \text {, SV } 2301\end{array}$ \\
\hline Apiaceae & Bunium ferulaceum Sibth. \& Sm. & İncirop & Akdeniz & - & $\begin{array}{l}\text { Deniz kıyısının bitimi, 40¹8'34.89"K, } \\
27^{\circ} 25^{\prime} 25.26 " \mathrm{D}, 8 \mathrm{~m}, 12.03 .2017 \text {, SV } 2007\end{array}$ \\
\hline Apiaceae & Crithmum maritimum L. & Denizteresi & - & LC & $\begin{array}{l}\text { Deniz kıyısı, kumullar, } 40^{\circ} 19^{\prime} 1.60^{\prime \prime K}, 27^{\circ} 24^{\prime} 14.12 " \mathrm{D} \text {, } \\
9 \mathrm{~m}, 15.03 .2017 \text {, sV } 2015\end{array}$ \\
\hline Apiaceae & Eryngium maritimum L. & Kum boğadikeni & - & LC & $\begin{array}{l}\text { Deniz kıyısı, kumullar, 40¹7'55.10"K, } \\
27^{\circ} 33^{\prime} 45.41^{\circ} \mathrm{D}, 1 \mathrm{~m}, 15.03 .2017 \text {, sV } 2017\end{array}$ \\
\hline Apiaceae & Cachrys cristata DC. & Tepeli çarşambaotu & D. Akdeniz & - & $\begin{array}{l}\text { Deniz kıyısının bitimi, } 40^{\circ} 18^{\prime} 5.59^{\prime \prime K}, 27^{\circ} 40^{\prime} 6.41 " \mathrm{D}, \\
72 \mathrm{~m}, 7.04 .2017 \text {, SV } 2037\end{array}$ \\
\hline Apiaceae & Oenanthe pimpinelloides $\mathrm{L}$. & Delimaydanoz & - & LC & $\begin{array}{l}\text { Kumsalın bitimi, } 40^{\circ} 19^{\prime} 3.88^{\prime \prime K}, 27^{\circ} 38^{\prime} 22.04^{\prime \prime} \mathrm{D}, 1 \mathrm{~m} \text {, } \\
\text { 21.03.2017, SV } 2023\end{array}$ \\
\hline Apiaceae & Scandix pecten-veneris L. & Zühretarağı & - & - & $\begin{array}{l}\text { Kumsalın bitimi, } 40^{\circ} 19^{\prime} 21.69 " \mathrm{~K}, 27^{\circ} 37^{\prime} 38.20^{\prime \prime} \mathrm{D}, 3 \\
\mathrm{~m}, 15.03 .2017 \text {, SV } 2020\end{array}$ \\
\hline Apocynaceae & Cynanchum acutum L. subsp. acutum & Bacırgan & - & LC & $\begin{array}{l}\text { Deniz kıyısının bitimi , } 40^{\circ} 18^{\prime} 39.55^{\prime K} \mathrm{~K} \\
27^{\circ} 39^{\prime} 15.96 " \mathrm{D}, 24.05 .2018,1 \mathrm{~m} \text {, SV } 2341\end{array}$ \\
\hline Araceae & Arum italicum Mill. & Domuzlahanası & - & - & $\begin{array}{l}\text { Kumsalın bitimi, } 40^{\circ} 18^{\prime} 34.87^{\prime \prime K}, 27^{\circ} 39^{\prime} 49.17^{\prime \prime D}, 2 \\
\mathrm{~m}, 7.04 .2017, \mathrm{SV} 2036\end{array}$ \\
\hline Asparagaceae & Ornithogalum pyrenaicum L. & Eşeksusamı & - & - & $\begin{array}{l}\text { Kumsalın bitimi, } 40^{\circ} 18^{\prime} 41.36^{\prime \prime K}, 27^{\circ} 39^{\prime} 23.31 " \mathrm{D}, 3 \\
\mathrm{~m}, 04.04 .2018 \text {, SV } 2302\end{array}$ \\
\hline Asparagaceae & Drimia maritima (L.) Stearn & Kumörümcekotu & Akdeniz & LC & $\begin{array}{l}\text { Kumsalda, } 40^{\circ} 19^{\prime} 0.73^{\prime \prime K}, 27^{\circ} 38^{\prime} 57.41 " \mathrm{D}, 1 \mathrm{~m}, \\
24.05 .2018, \text { SV } 2342\end{array}$ \\
\hline Asparagaceae & Prospero autumnale (L.) Speta & Güzsümbülü & Akdeniz & - & $\begin{array}{l}\text { Kumsalın bitimi, } 40^{\circ} 18^{\prime} 34.80^{\prime \prime K}, 27^{\circ} 39^{\prime} 55.73^{\prime \prime D}, 3 \\
\mathrm{~m}, 08.04 .2017 \text {, SV } 2042\end{array}$ \\
\hline Asteraceae & Otanthus maritimus (L.) Hoffm. \& Lk. subsp. maritimus & Çocukotu & - & - & $\begin{array}{l}\text { Kumsalın bitimi, } 40^{\circ} 18^{\prime} 33.13^{\prime \prime K}, 27^{\circ} 39^{\prime} 54.04 " \mathrm{D}, 3 \\
\mathrm{~m}, 05.04 .2018 \text {, SV } 2321\end{array}$ \\
\hline Asteraceae & Cota altissima (L.) J.Gay & Köpekpapatyası & - & - & $\begin{array}{l}\text { Kumsallarda, } 40^{\circ} 18^{\prime} 42.20^{\prime \prime K}, 27^{\circ} 39^{\prime} 37.15^{\prime \prime} \mathrm{D}, 1 \mathrm{~m} \text {, } \\
\text { 13.06.2017, SV } 2086\end{array}$ \\
\hline Asteraceae & Anthemis rigida (Sibth. \& Sm.) Boiss. \& Heldr. & Diripapatya & D. Akdeniz & - & $\begin{array}{l}\text { Kumsallarda, } 40^{\circ} 18^{\prime} 47.01^{\prime \prime K}, 27^{\circ} 39^{\prime} 25.54 " \mathrm{D}, 2 \mathrm{~m} \text {, } \\
\text { 08.04.2017, SV } 2044\end{array}$ \\
\hline
\end{tabular}


Çizelge 2 (Devamı). Gönen Deltasında tespit edilen kumul bitki floras

\begin{tabular}{|c|c|c|c|c|c|}
\hline Familya & Bilimsel İsim & Türkçe İsim & $\begin{array}{l}\text { Fitocoğrafik } \\
\text { Elementi }\end{array}$ & $\begin{array}{l}\text { Tehlike Kategorisi } \\
\text { (IUCN' e göre) }\end{array}$ & $\begin{array}{l}\text { Lokalite ve toplayıcı numaraları } \\
\text { (A1(A) Balıkesir: Gönen Deltası }\end{array}$ \\
\hline Asteraceae & Cota tinctoria (L.) J.Gay subsp. tinctoria & Boyacıpapatyası & - & 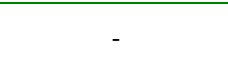 & $\begin{array}{l}\text { Kumsallarda, } 40^{\circ} 18^{\prime} 56.45^{\prime \prime K}, 27^{\circ} 39^{\prime} 3.55^{\prime \prime} \mathrm{D}, 1 \mathrm{~m}, \\
13.06 .2017 \text {, SV } 2088\end{array}$ \\
\hline Asteraceae & Artemisia santonicum L. & Denizyavşanı & Av.-Sib. & LC & $\begin{array}{l}\text { Kumsalda, } 40^{\circ} 19^{\prime} 30.16^{\prime \prime K}, 27^{\circ} 38^{\prime} 10.40^{\prime \prime} \mathrm{D}, 1 \mathrm{~m}, \\
15.05 .2017, \mathrm{SV} 2052\end{array}$ \\
\hline Asteraceae & Asteriscus aquaticus (L.) Less. & Saritop & Akdeniz & - & $\begin{array}{l}\text { Kumsal bitimi, su kenarı, } 40^{\circ} 19^{\prime} 31.34^{\prime \prime K} \\
27^{\circ} 38^{\prime} 4.80^{\prime \prime D}, 2 \mathrm{~m}, 08.04 .2017 \text {, SV } 2047\end{array}$ \\
\hline Asteraceae & Tripolium pannonicum (Jacq.) Dobroczajeva & Bataklıkpapatyası & - & - & $\begin{array}{l}\text { Kumsalda, } 40^{\circ} 19^{\prime} 6.05^{\prime \prime K}, 27^{\circ} 38^{\prime} 49.39^{\prime \prime D}, 1 \mathrm{~m}, \\
15.05 .2017, \text { sV } 2054\end{array}$ \\
\hline Asteraceae & Carlina gummifera (L.) Less. & Sakızkeyganası & Akdeniz & LC & $\begin{array}{l}\text { Kumsal dışında, } 40^{\circ} 19^{\prime} 19.35^{\prime \prime K}, 27^{\circ} 36^{\prime} 4.56 " \mathrm{D}, 1 \mathrm{~m} \text {, } \\
\text { 21.03.2017, SV } 2024\end{array}$ \\
\hline Asteraceae & Bellis annua $\mathrm{L}$. & Akbubeçlik & Akdeniz & - & $\begin{array}{l}\text { Kumsallık alanlarda ve dışında, } 40^{\circ} 15^{\prime} 50.74 " \mathrm{~K} \\
27^{\circ} 40^{\prime} 24.49^{\prime \prime D}, 111 \mathrm{~m}, 26.05 .2018 \text {, SV } 2390\end{array}$ \\
\hline Asteraceae & Cardopatium corymbosum (L.) Pers. & Kurtludiken & D. Akdeniz & - & $\begin{array}{l}\text { Kumsallık alanlarda ve dışında, } 40^{\circ} 18^{\prime} 38.39 " K \\
27^{\circ} 35^{\prime} 44.44 " \mathrm{D}, 2 \mathrm{~m}, 13.06 .2017, \text { SV } 2090\end{array}$ \\
\hline Asteraceae & Carduus acicularis Bertol. & Sivrikangal & Akdeniz & - & $\begin{array}{l}\text { Kumsalın bitimi, } 40^{\circ} 19^{\prime} 23.29 " \mathrm{~K}, 27^{\circ} 36^{\prime} 12.14 " \mathrm{D}, 1 \\
\mathrm{~m}, 21.03 .2017, \mathrm{~S} V 2025\end{array}$ \\
\hline Asteraceae & Centaurea spinosa L. & Denizgeveni & - & - & $\begin{array}{l}\text { Kumsalın bitimi, } 40^{\circ} 19^{\prime} 14.03^{\prime \prime K}, 27^{\circ} 35^{\prime} 47.21 " \mathrm{D}, 1 \mathrm{~m} \text {, } \\
\text { 29.05.2018, 08.04.2017, SV } 2411\end{array}$ \\
\hline Asteraceae & Crepis commutata (Spreng.) W. Greuter & Delikıskıs & - & - & $\begin{array}{l}\text { Kumsalın bitimi, } 40^{\circ} 18^{\prime} 26.93 " K, 27^{\circ} 34^{\prime} 25.07^{\prime \prime} \mathrm{D}, 1 \\
\mathrm{~m}, 26.05 .2018, \text { SV } 2394\end{array}$ \\
\hline Asteraceae & Hedypnois rhagadioloides (L.) F.W.Schmidt subsp. rhagadioloides & Sünnetlice & Akdeniz & - & $\begin{array}{l}\text { Kumsallık alanlarda ve dışında, } 40^{\circ} 13^{\prime} 22.74 " \mathrm{~K} \\
27^{\circ} 36^{\prime} 26.57^{\prime \prime D}, 146 \mathrm{~m}, 12.06 .2017 \text {, SV } 2074\end{array}$ \\
\hline Asteraceae & Helichrysum orientale (L.) DC. & Sarısolmaz & Akdeniz & - & $\begin{array}{l}\text { Kumsalın bitimi, } 40^{\circ} 19^{\prime} 17.02^{\prime \prime K}, 27^{\circ} 35^{\prime} 53.28^{\prime \prime} \mathrm{D}, 1 \mathrm{~m} \text {, } \\
\text { 15.05.2017, SV } 2055\end{array}$ \\
\hline Asteraceae & Helminthotheca echioides (L.) Holub & Billurdüğme & - & - & $\begin{array}{l}\text { Kumsalın bitimi, } 40^{\circ} 18^{\prime} 16.13^{\prime \prime K}, 27^{\circ} 34^{\prime} 7.31^{\prime \prime} \mathrm{D}, 2 \mathrm{~m} \text {, } \\
\text { 29.05.2018, SV } 2410\end{array}$ \\
\hline Asteraceae & Hypochaeris achyrophorus L. & Sarıhindiba & Akdeniz & - & $\begin{array}{l}\text { Kumsalın bitimi, } 40^{\circ} 17^{\prime} 55.42^{\prime \prime K}, 27^{\circ} 33^{\prime} 51.13^{\prime \prime} \mathrm{D}, 1 \\
\mathrm{~m}, 28.05 .2018 \text {, SV } 2406\end{array}$ \\
\hline Asteraceae & Hypochaeris glabra L. & Cıbıldağmarulu & - & - & $\begin{array}{l}\text { Kumsalın bitimi, } 40^{\circ} 19^{\prime} 10.40^{\prime K}, 27^{\circ} 35^{\prime} 41.75^{\prime \prime} \mathrm{D}, 1 \mathrm{~m} \text {, } \\
\text { 29.05.2018, SV } 2415\end{array}$ \\
\hline Asteraceae & Senecio vernalis Waldst. et Kit. & Kanaryaotu & - & - & $\begin{array}{l}\text { Kumsalın bitimi, } 40^{\circ} 17^{\prime} 53.84^{\prime \prime K}, 27^{\circ} 33^{\prime} 39.41^{\prime \prime} \mathrm{D}, 1 \mathrm{~m} \text {, } \\
\text { 28.05.2018, SV } 2404\end{array}$ \\
\hline Asteraceae & Xanthium strumarium L. & Kocapitrak & - & - & $\begin{array}{l}\text { Kumsalın bitimi, } 40^{\circ} 19^{\prime} 0.70^{\prime \prime K}, 27^{\circ} 35^{\prime} 22.48^{\prime \prime} \mathrm{D}, 1 \mathrm{~m} \text {, } \\
29.05 .2018 \text {, SV } 2450\end{array}$ \\
\hline Asteraceae & Dittrichia graveolens (L.) W. Greuter & Delisarıot & Akdeniz & - & $\begin{array}{l}\text { Kumsalın bitimi, } 40^{\circ} 17^{\prime} 47.06 " \mathrm{~K}, 27^{\circ} 33^{\prime} 17.37^{\prime \prime D}, 1 \\
\mathrm{~m}, 16.05 .2017 \text {, SV } 2063\end{array}$ \\
\hline Boraginaceae & Echium angustifoilum Mill. subsp. angustifolium & Agres & D. Akdeniz & - & $\begin{array}{l}\text { Kumsalın bitimi, } 40^{\circ} 19^{\prime} 17.92^{\prime \prime K}, 27^{\circ} 35^{\prime} 58.68 " \mathrm{D}, 1 \\
\mathrm{~m}, 29.05 .2018 \text {, SV } 2452\end{array}$ \\
\hline Brassicaceae & Cakile maritima Scop. & Kumteresi & - & - & $\begin{array}{l}\text { Kumsalda, } 40^{\circ} 19^{\prime} 4.81^{\prime \prime K}, 27^{\circ} 38^{\prime} 52.47 " \mathrm{D}, 1 \mathrm{~m}, \\
12.06 .2017 \text {, SV } 2075\end{array}$ \\
\hline Brassicaceae & Eruca vesicaria (L.) Cav. & Roka & - & LC & $\begin{array}{l}\text { Kumsalda, } 40^{\circ} 19^{\prime} 13.73^{\prime \prime K}, 27^{\circ} 38^{\prime} 37.50^{\prime \prime D}, 1 \mathrm{~m}, \\
\text { 14.06.2017, SV } 2101\end{array}$ \\
\hline Brassicaceae & Malcolmia flexuosa (Sm.) Sm. & Kayaşebboyu & D. Akdeniz & - & $\begin{array}{l}\text { Kumsalda, } 40^{\circ} 19^{\prime} 23.24^{\prime \prime K}, 27^{\circ} 38^{\prime} 20.53^{\prime \prime D}, 1 \mathrm{~m}, \\
12.06 .2017 \text {, SV } 2077\end{array}$ \\
\hline Brassicaceae & Matthiola sinuata (L.) R.Br. & Oyalı Şebboy & - & - & $\begin{array}{l}\text { Kumsalda, } 40^{\circ} 19^{\prime} 10.26^{\prime \prime K}, 27^{\circ} 38^{\prime} 41.88^{\prime \prime} \mathrm{D}, 1 \mathrm{~m}, \\
\text { 24.05.2018, SV } 2344\end{array}$ \\
\hline Brassicaceae & Matthiola tricuspidata (L.) R. Br. & Öküzşebboyu & Akdeniz & - & $\begin{array}{l}\text { Kumsalda, } 40^{\circ} 19^{\prime} 7.56^{\prime \prime K}, 27^{\circ} 38^{\prime} 43.79 " \mathrm{D}, 1 \mathrm{~m}, \\
24.05 .2018 \text {, SV } 2343\end{array}$ \\
\hline
\end{tabular}


Çizelge 2 (Devamı). Gönen Deltasında tespit edilen kumul bitki florası

\begin{tabular}{|c|c|c|c|c|c|}
\hline Familya & Bilimsel İsim & Türkçe İsim & $\begin{array}{l}\text { Fitocoğrafik } \\
\text { Elementi }\end{array}$ & $\begin{array}{l}\text { Tehlike Kategorisi } \\
\text { (IUCN' e göre) }\end{array}$ & $\begin{array}{l}\text { Lokalite ve toplayıcı numaraları } \\
\text { (A1(A) Balıkesir: Gönen Deltası }\end{array}$ \\
\hline Brassicaceae & Raphanus raphanistrum L. subsp. raphanistrum & Eşekturpu & - & LC & $\begin{array}{l}\text { Kumsallık alanlarda ve dışında, } 40^{\circ} 15^{\prime} 31.52^{\prime \prime K} \text {, } \\
27^{\circ} 38^{\prime} 55.11^{\prime \prime D}, 53 \mathrm{~m}, 04.06 .2018 \text {, SV } 2502\end{array}$ \\
\hline Brassicaceae & Rapistrum rugosum (L.) All. & Kediturpu & - & - & $\begin{array}{l}\text { Kumsallık alanlarda ve dişında, } 40^{\circ} 14^{\prime} 0.09^{\prime \prime K} \\
27^{\circ} 37^{\prime} 32.97^{\prime \prime D}, 101 \mathrm{~m}, 04.06 .2018 \text {, SV } 2505\end{array}$ \\
\hline Campanulaceae & Jasione montana L. subsp. montana & Dağgökçesi & - & - & $\begin{array}{l}\text { Kumsallık alanlarda ve dışında, } 40^{\circ} 19^{\prime} 22.63^{\prime \prime} \mathrm{K}, \\
27^{\circ} 38^{\prime} 15.36^{\prime \prime} \mathrm{D}, 1 \mathrm{~m}, 04.06 .2018, \mathrm{SV} 2506\end{array}$ \\
\hline Caryophyllaceae & Sagina maritima G.Don & Arsızsaginotu & - & - & $\begin{array}{l}\text { Kumsalda, } 40^{\circ} 19^{\prime} 2.12^{\prime \prime K}, 27^{\circ} 38^{\prime} 56.69^{\prime \prime} \mathrm{D}, 1 \mathrm{~m}, \\
16.05 .2017, \text { SV } 2064\end{array}$ \\
\hline Caryophyllaceae & Spergula arvensis L. & Tarlakişnişi & - & - & $\begin{array}{l}\text { Kumsalda, } 40^{\circ} 19^{\prime} 1.66^{\prime \prime K}, 27^{\circ} 38^{\prime} 57.79^{\prime \prime} \mathrm{D}, 1 \mathrm{~m}, \\
24.05 .2018, \text { SV } 2345\end{array}$ \\
\hline Caryophyllaceae & Spergularia marina (L.) Besser & Sahilremilotu & - & LC & $\begin{array}{l}\text { Kumsalda, } 40^{\circ} 18^{\prime} 58.97^{\prime \prime K}, 27^{\circ} 35^{\prime} 7.56^{\prime \prime} \mathrm{D} \\
16.05 .2017 \text {, SV } 2066\end{array}$ \\
\hline Cistaceae & Tuberaria guttata (L.) Fourr. & Karagözgülü & - & - & $\begin{array}{l}\text { Kumsalın bitimi, } 40^{\circ} 18^{\prime} 10.09^{\prime \prime K}, 27^{\circ} 34^{\prime} 57.04^{\prime \prime} \mathrm{D}, 1 \\
\mathrm{~m}, 04.06 .2018, \mathrm{SV} 2510\end{array}$ \\
\hline Convolvulaceae & Calystegia soldanella (L.) R.Br. & Kumsarmaşığı & - & - & $\begin{array}{l}\text { Kumsallık alanlarda ve dışında, } 40^{\circ} 17^{\prime} 6.11^{\prime \prime} \mathrm{K} \\
27^{\circ} 34^{\prime} 59.09^{\prime \prime} \mathrm{D}, 17 \mathrm{~m}, 12.06 .2017, \text { sV } 2076\end{array}$ \\
\hline Crassulaceae & Sedum litoreum Guss. & Kıyıkoruğu & Akdeniz & - & $\begin{array}{l}\text { Kumsalda, } 40^{\circ} 18^{\prime} 39.37^{\prime \prime K}, 27^{\circ} 27^{\prime} 52.95^{\prime \prime D}, 1 \text { m, } \\
\text { 15.05.2017, SV } 2051\end{array}$ \\
\hline Cucurbitaceae & Bryonia alba L. & Akhaylin & Avrupa-Sibirya & - & $\begin{array}{l}\text { Kumsal dışında, } 40^{\circ} 15^{\prime} 47.94 " \mathrm{~K}, 27^{\circ} 34^{\prime} 44.74^{\prime \prime} \mathrm{D}, 97 \\
\mathrm{~m}, 15.05 .2017 \text {, SV } 2054\end{array}$ \\
\hline Cyperaceae & Bolboschoenus maritimus (L.) Palla subsp. maritimus & Sandalyesazı & - & LC & $\begin{array}{l}\text { Kumsalda, } 40^{\circ} 18^{\prime} 19.77^{\prime \prime K}, 27^{\circ} 29^{\prime} 30.84^{\prime \prime D}, 1 \text { m, } \\
\text { 15.05.2017, SV } 2053\end{array}$ \\
\hline Cyperaceae & Eleocharis palustris (L.) Roem. \& Schult.subsp. palustris & Delisaz & - & LC & $\begin{array}{l}\text { Kumsalda, } 40^{\circ} 19^{\prime} 54.65^{\prime \prime} \mathrm{K}, 27^{\circ} 24^{\prime} 25.00^{\prime \prime} \mathrm{D}, 1 \mathrm{~m}, \\
15.05 .2017, \mathrm{SV} 2060\end{array}$ \\
\hline Euphorbiaceae & Euphorbia paralias L. & Kumsütleğeni & Akdeniz & - & $\begin{array}{l}\text { Kumsalda, } 40^{\circ} 18^{\prime} 19.90^{\prime \prime} \mathrm{K}, 27^{\circ} 45^{\prime} 15.94 " \mathrm{D}, 1 \mathrm{~m}, \\
12.06 .2017, \mathrm{SV} 2078\end{array}$ \\
\hline Euphorbiaceae & Euphorbia peplis L. & Kıyısütleğeni & Akdeniz & - & $\begin{array}{l}\text { Kumsalda, } 40^{\circ} 18^{\prime} 57.05^{\prime \prime K}, 27^{\circ} 39^{\prime} 5.53^{\prime \prime} \mathrm{D}, 1 \mathrm{~m}, \\
04.04 .2018, \text { SV } 2304\end{array}$ \\
\hline Fabaceae & Hippocrepis unisiliquosa L. subsp. unisiliquosa & Atnalı & - & - & $\begin{array}{l}\text { Kumsallık alanlarda ve dışında, } 40^{\circ} 19^{\prime} 10.27^{\prime \prime K} \text {, } \\
27^{\circ} 38^{\prime} 26.63^{\prime \prime D}, 1 \mathrm{~m}, 29.05 .2018 \text {, SV } 2412\end{array}$ \\
\hline Fabaceae & Medicago marina L. & Sahilyoncası & - & LC & $\begin{array}{l}\text { Kumsalda, } 40^{\circ} 19^{\prime} 3.39^{\prime \prime} \mathrm{K}, 27^{\circ} 38^{\prime} 51.61 " \mathrm{D}, 1 \mathrm{~m}, \\
12.06 .2017, \text { SV } 2079\end{array}$ \\
\hline Frankeniaceae & Frankenia hirsuta L. & Tülpembe & - & - & $\begin{array}{l}\text { Kumsalda, } 40^{\circ} 19^{\prime} 0.45^{\prime \prime K}, 27^{\circ} 39^{\prime} 0.37^{\prime \prime D}, 1 \mathrm{~m}, \\
26.05 .2018 \text {, SV } 2398\end{array}$ \\
\hline Gentianaceae & Centaurium maritimum (L.) Fritsch & Sarıgelindüğmesi & Akdeniz & - & $\begin{array}{l}\text { Kumsallık alanlarda ve dışında, } 40^{\circ} 18^{\prime} 54.07 " \mathrm{~K} \\
27^{\circ} 38^{\prime} 26.38^{\prime \prime} \mathrm{D}, 1 \mathrm{~m}, 16.05 .2017, \mathrm{SV} 2062\end{array}$ \\
\hline Juncaceae & Juncus acutus L. subsp. acutus & Kofa & - & LC & $\begin{array}{l}\text { Sulak alanlar, } 40^{\circ} 17^{\prime} 53.04^{\prime \prime K}, 27^{\circ} 39^{\prime} 51.69^{\prime \prime D}, 69 \mathrm{~m} \text {, } \\
04.06 .2018 \text {, SV } 2525\end{array}$ \\
\hline Juncaceae & Juncus bufonius L. & Kamır & - & - & $\begin{array}{l}\text { Sulak alanlar, } 40^{\circ} 17^{\prime} 44.66^{\prime \prime K}, 27^{\circ} 39^{\prime} 49.05^{\prime \prime D}, 107 \mathrm{~m} \text {, } \\
26.05 .2018 \text {, SV } 2391\end{array}$ \\
\hline Juncaceae & Juncus capitatus Weigel & Topakkofa & - & - & $\begin{array}{l}\text { Sulak alanlar, } 40^{\circ} 17^{\prime} 52.08^{\prime \prime K}, 27^{\circ} 39^{\prime} 16.02^{\prime \prime} \mathrm{D}, 58 \mathrm{~m}, \\
26.05 .2018 \text {, SV } 2392\end{array}$ \\
\hline Papaveraceae & Glaucium flavum Crantz & Gündürmelalesi & - & LC & $\begin{array}{l}\text { Kumsallık alanlarda ve dışında, } 40^{\circ} 17^{\prime} 15.46^{\prime \prime K} \\
27^{\circ} 35^{\prime} 47.76 \text { "D, } 7 \mathrm{~m}, 21.03 .2017, \text { SV } 2021\end{array}$ \\
\hline Plantaginaceae & Plantago afra $\mathrm{L}$. & Ateşyaprağı & - & LC & $\begin{array}{l}\text { Kumsallık alanlarda ve dışında, } 40^{\circ} 16^{\prime} 47.21^{\prime \prime K}, \\
27^{\circ} 37^{\prime} 17.98^{\prime \prime} \mathrm{D}, 66 \mathrm{~m}, 21.03 .2017, \mathrm{SV} 2022\end{array}$ \\
\hline Plantaginaceae & Plantago lagopus L. & Kırkdamarotu & Akdeniz & - & $\begin{array}{l}\text { Kumsallık alanlarda ve dışında, } 40^{\circ} 18^{\prime} 3.37^{\prime \prime K} \\
27^{\circ} 34^{\prime} 7.65^{\prime \prime D}, 2 \mathrm{~m}, 25.05 .2018, \text { SV } 2363\end{array}$ \\
\hline
\end{tabular}


Çizelge 2 (Devamı). Gönen Deltasında tespit edilen kumul bitki florası

\begin{tabular}{|c|c|c|c|c|c|}
\hline Familya & Bilimsel İsim & Türkçe İsim & $\begin{array}{l}\text { Fitocoğrafik } \\
\text { Elementi }\end{array}$ & $\begin{array}{l}\text { Tehlike Kategorisi } \\
\text { (IUCN' e göre) }\end{array}$ & $\begin{array}{l}\text { Lokalite ve toplayıcı numaraları } \\
\text { (A1(A) Balıkesir: Gönen Deltası }\end{array}$ \\
\hline Plumbaginaceae & Limonium narbonense Mill. & Sahilkaranfili & - & - & $\begin{array}{l}\text { Kumsalllk alanlarda ve dışında, } 40^{\circ} 17^{\prime} 23.53^{\prime \prime K}, \\
27^{\circ} 33^{\prime} 19.43^{\prime \prime D}, 27 \mathrm{~m}, 25.05 .2018 \text {, SV } 2362\end{array}$ \\
\hline Plumbaginaceae & Limonium virgatum (Willd.) Four & Cilizot & Akdeniz & - & $\begin{array}{l}\text { Kumsallık alanlarda ve dışında, } 40^{\circ} 17^{\prime} 27.64 " \mathrm{~K}, \\
27^{\circ} 32^{\prime} 13.10^{\prime \prime} \mathrm{D}, 33 \mathrm{~m}, 25.05 .2018, \mathrm{SV} 2364\end{array}$ \\
\hline Poaceae & Aegilops biuncialis Vis. & İkikılçık & - & LC & $\begin{array}{l}\text { Kumsallık alanlarda ve dışında, } 40^{\circ} 15^{\prime} 54.99^{\prime \prime K} \text {, } \\
27^{\circ} 38^{\prime} 59.49^{\prime \prime} \mathrm{D}, 23 \mathrm{~m}, 25.05 .2018 \text {, SV } 2366\end{array}$ \\
\hline Poaceae & Aeluropus littoralis (Gouan) Parl. & Sahilayrı̆̆ı & - & LC & $\begin{array}{l}\text { Kumsallık alanlarda ve dışında, } 40^{\circ} 18^{\prime} 49.91^{\prime \prime K} \\
27^{\circ} 38^{\prime} 34.80^{\prime \prime} \mathrm{D}, 2 \mathrm{~m}, 25.05 .2018 \text {, SV } 2365\end{array}$ \\
\hline Poaceae & Arundo donax $\mathrm{L}$. & Kargı & - & LC & $\begin{array}{l}\text { Sulak alanlar, } 40^{\circ} 18^{\prime} 58.97^{\prime \prime K}, 27^{\circ} 35^{\prime} 32.76^{\prime \prime} \mathrm{D}, 1 \mathrm{~m} \text {, } \\
\text { 12.03.2017, SV } 2006\end{array}$ \\
\hline Poaceae & Echinochloa crus-galli (L.) P. Beauv. & Darıcan & - & LC & $\begin{array}{l}\text { Kumsallık alanlarda ve dışında, } 40^{\circ} 18^{\prime} 46.13^{\prime \prime K} \\
27^{\circ} 37^{\prime} 56.34^{\prime \prime D}, 2 \mathrm{~m}, 21.03 .2017, \mathrm{SV} 2026\end{array}$ \\
\hline Poaceae & Cynodon dactylon (L.) Pers. & Köpekdişi & - & - & $\begin{array}{l}\text { Kumsallık alanlarda ve dışında, } 40^{\circ} 19^{\prime} 2.31^{\prime \prime K} \text {, } \\
27^{\circ} 36^{\prime} 22.25^{\prime \prime D}, 1 \mathrm{~m}, 26.05 .2018, \text { SV } 2093\end{array}$ \\
\hline Poaceae & Thinopyrum flaccidifolium (Boiss. \& Heldr.) Moustakas & Bataklıkcicorası & D. Akdeniz & - & $\begin{array}{l}\text { Kumsallık alanlarda ve dışında, } 40^{\circ} 18^{\prime} 49.96^{\prime \prime} \mathrm{K} \\
27^{\circ} 36^{\prime} 50.41 " \mathrm{D}, 2 \mathrm{~m}, 21.03 .2017 \text {, SV } 2029\end{array}$ \\
\hline Polygonaceae & Polygonum maritimum L. & Sicimlik & - & - & $\begin{array}{l}\text { Kumsallık alanlarda, } 40^{\circ} 19^{\prime} 27.13^{\prime \prime K}, 27^{\circ} 36^{\prime} 36.04^{\prime \prime D} \text {, } \\
\text { 16.05.2017, SV } 2065\end{array}$ \\
\hline Polygonaceae & Rumex pulcher L. subsp. raulini (Boiss.) Rech.f. & Kuzu Kulağı & - & LC & $\begin{array}{l}\text { Kumsallık alanlarda ve dışında, } 40^{\circ} 18^{\prime} 38.23 " \mathrm{~K} \\
27^{\circ} 34^{\prime} 43.22^{\prime \prime} \mathrm{D}, 1 \mathrm{~m}, 04.04 .2018, \mathrm{SV} 2306\end{array}$ \\
\hline Rosaceae & Sarcopoterium spinosum (L.) Spach & Abdestbozan & - & - & $\begin{array}{l}\text { Kumsallık alanlarda ve dışında, } 40^{\circ} 18^{\prime} 0.56 " \mathrm{~K}, \\
27^{\circ} 37^{\prime} 39.04^{\prime \prime D}, 4 \mathrm{~m}, 16.05 .2017, \mathrm{SV} 2069\end{array}$ \\
\hline Rubiaceae & Galium caminianum Schult. \& Schult.f.. & Bursasünnetlicesi & D. Akdeniz & - & $\begin{array}{l}\text { Kumsallık alanlarda ve dışında, } 40^{\circ} 17^{\prime} 19.16^{\prime \prime} \mathrm{K} \\
27^{\circ} 35^{\prime} 14.76^{\prime \prime D}, 9 \mathrm{~m}, 16.05 .2017, \text { SV } 2070\end{array}$ \\
\hline Rubiaceae & Valantia hispida L. & Kıllıörenotu & Akdeniz & - & $\begin{array}{l}\text { Kumsal dışında, } 40^{\circ} 18^{\prime} 20.10^{\prime \prime K}, 27^{\circ} 34^{\prime} 39.01^{\prime \prime D} \text {, } \\
12.03 .2017,2 \mathrm{~m} \text {, SV } 2002\end{array}$ \\
\hline Santalaceae & Thesium humile Vahl. & Bodurgüvelek & Akdeniz & - & $\begin{array}{l}\text { Kumsal dışında, } 40^{\circ} 18^{\prime} 38.53^{\prime \prime K}, 27^{\circ} 34^{\prime} 57.80^{\prime \prime D}, 1 \mathrm{~m} \text {, } \\
\text { 19.05.2018, SV } 2331\end{array}$ \\
\hline Selaginellaceae & Selaginella denticulata (L.) Spring & Dişliselagin & Akdeniz & LC & $\begin{array}{l}\text { Kumsallık alanlar, } 40^{\circ} 18^{\prime} 47.36^{\prime \prime K}, 27^{\circ} 34^{\prime} 43.38^{\prime \prime D}, 1 \\
\mathrm{~m}, 12.03 .2017, \text { SV } 2009\end{array}$ \\
\hline Tamaricaceae & Tamarix tetrandra Pall. ex Bieb. & Gezik & - & LC & $\begin{array}{l}\text { Kumsallık alanlarda ve dışında, } 40^{\circ} 18^{\prime} 53.52^{\prime \prime K} \text {, } \\
27^{\circ} 35^{\prime} 36.88^{\prime \prime} \mathrm{D}, 1 \mathrm{~m}, 15.05 .2017, \text { SV } 2056\end{array}$ \\
\hline Xanthorrhoeaceae & Asphodelus aestivus Brot. & Kirgiçkökü & - & LC & $\begin{array}{l}\text { Kumsallık alanlarda ve dışında, } 40^{\circ} 15^{\prime} 24.00^{\prime \prime K} \\
27^{\circ} 41^{\prime} 41.37^{\prime \prime D}, 116 \mathrm{~m}, 11.03 .2017 \text {, SV } 1997\end{array}$ \\
\hline
\end{tabular}




\section{TARTIŞMA ve SONUÇ}

Sonuç olarak alanda; 32 familyaya ait 81 cins ve 89 takson tespit edilmiştir. En çok takson içeren ilk üç familya; Asteraceae (21), Brassicaceae (7) ve Amaranthaceae (6), en çok takson içeren cins ise Juncus ( 3 takson) olup bunu 2 taksonla Allium, Cota, Hypochaeris, Limonium, Matthiola, Plantago, Euphorbia ve Salsola türleri takip etmektedir (Şekil 2,3). Çalışma alanımıza yakın olan Çanakkale'de önemli kumul ve tuzcul alanların florası ve ekolojisi üzerine yapılan bir çalışmada ise bizim bulgulardan farklı olarak; toplam 51 familya, 164 cins ve 257 takson tespit edilmiş, ilk üç familyanın Poaceae, Asteraceae ve Fabaceae olduğu görülmüştür (Özmen ve Uysal 2012).

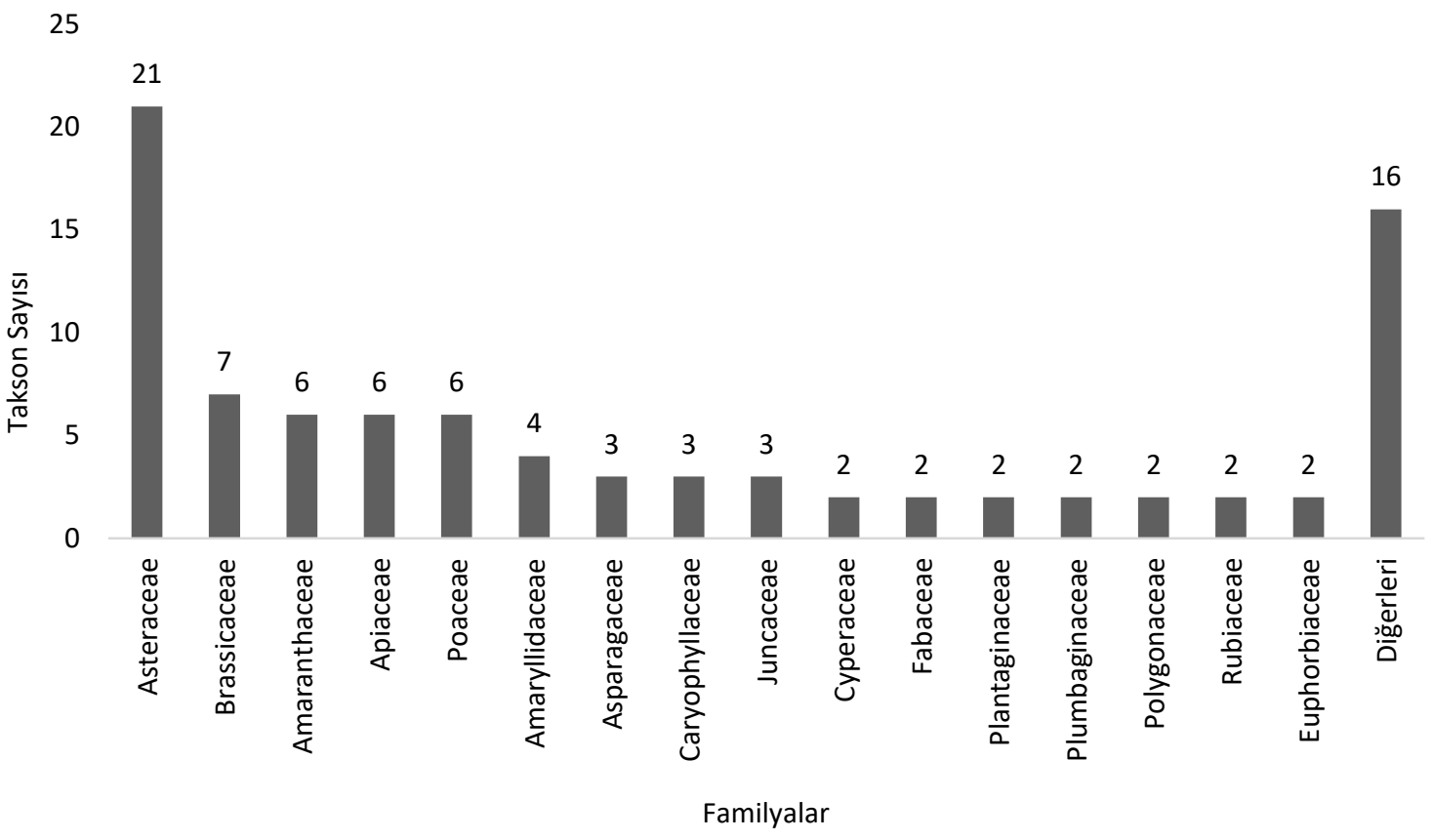

Şekil 2. Kumul alanlarda tespit edilen taksonların familya bazında dağılımı

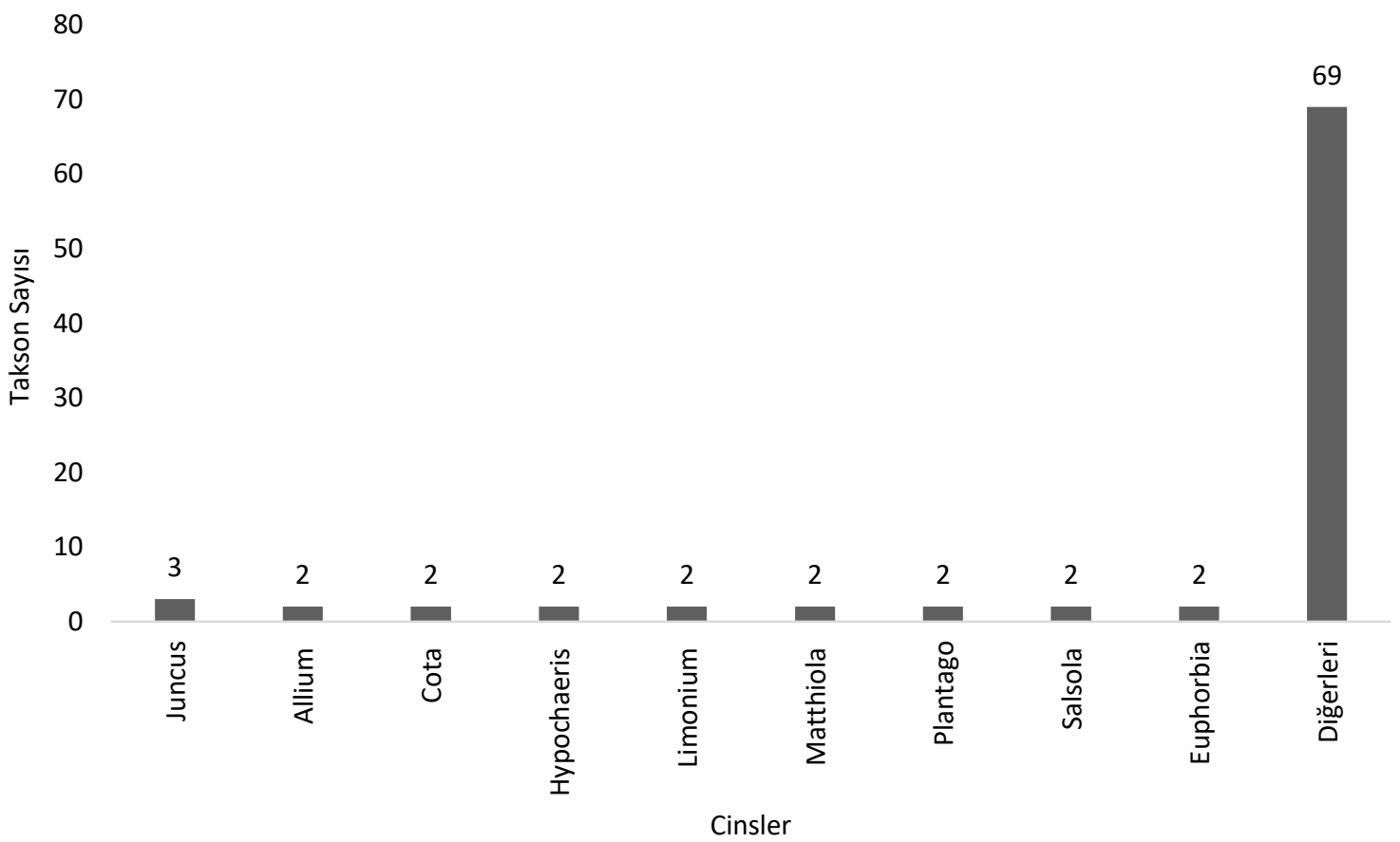

Şekil 3. Kumul alanlarda tespit edilen cinsler ve içerdikleri takson sayıları. 
Taksonların fitocoğrafik bölgelerine dağılışı; Akdeniz Elementi \%33.7 (30 takson), Avrupa-Sibirya Elementi \%2.2 (2 takson) ile geniş yayılışlı ve bilinmeyenler \%64.1 (57 takson) şeklindedir. Gönen kıyı kumulları ön ve arka kumulları şeklinde ayrılmıştır. Deniz kıyı çizgisinden ön kumula doğru 5-10 m'lik bir genişlikten sonra arka kumul kısmına geçiş olmaktadır. Ön kumullarda daha çok tek yıllık efemeral bitkiler gözlenmekte, arka kumullara doğru ise çok yıllık ve odunsu türlere rastlanmaktadır. Çalışma alanımıza yakın olan Çanakkale'de kumul ve tuzcul alanlarda tespit edilen bitki taksonlarının; \%35'i Akdeniz, $\% 16$ 'sı geniş yayılışlı, \%5'i Avrupa- Sibirya fitocoğrafik bölgesi ve $\% 1^{\prime} i$ de kozmopolit türler, $\% 43^{\prime} u ̈$ ise fitocoğrafik bölgesi tespit edilemeyen türlerdir (Özmen ve Uysal 2012).
Çalışma alanında IUCN (2019)' a göre taksonların 27 (\%30'u)' si LC (Düşük Risk) tehlike kategorisinde yer almaktadır. Çalışma alanında yüksek risk kategorilerinde yer alan türlere rastlanmamıştır. Bununla birlikte alan kumul ekosistemler açısından önemli bir alandır. Türlerin yaşam alanları olan kumul habitatlara zarar veren sahilden kum çekme, plaj düzenlemesi gibi faaliyetlerden kaçınılmalıdır. Bölgedeki kumul alanların karakteristik florasında Brassicaceae, Asteraceae, Plantaginaceae ve Amaranthaceae familyaları ağırlıktadır. Alandaki kumul bitki topluluğu içerisinde; Cakile maritima, Kali turgida ve Atriplex portulacoides önemli baskın türlerdir (Şekil 4). Kumul bitki türlerinden Pancratium maritimum ise tehdit altındadır. İç kısımdaki sabit kumul çayırlıklarda yer yer Sarcopoterium spinosum, Asphodelus aestivus, Xanthium strumarium ve Bryonia alba toplulukları bulunmaktadır.

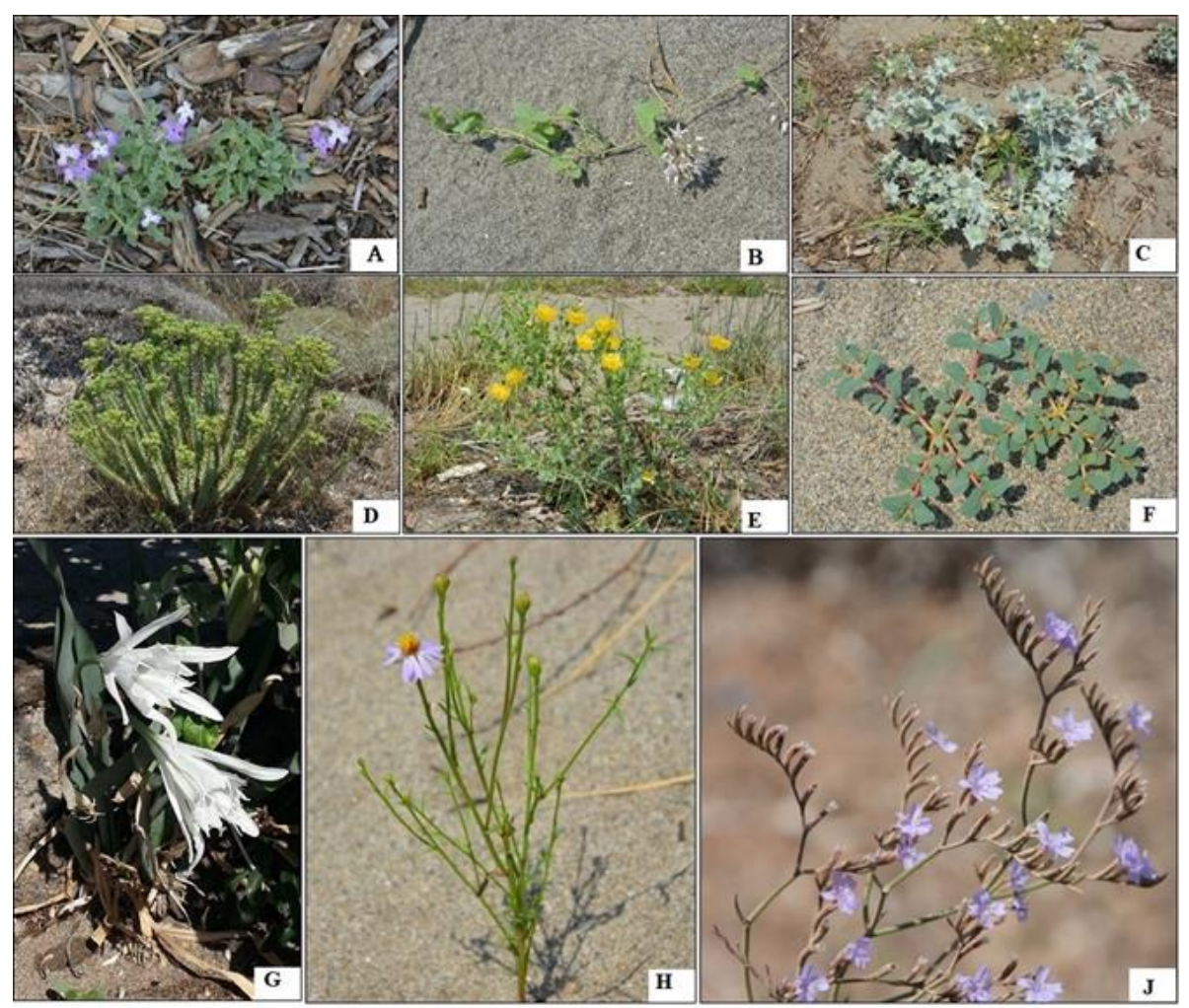

Şekil 4. Gönen Deltası kumul bitkileri: A) Matthiola tricuspidata, B) Cynanchum acutum, C) Eryngium maritimum, D) Euphorbia paralias, E) Glaucium flavum, F) Euphorbia peplis G) Pancratium maritimum, H) Tripolium pannonicum, J) Limonium virgatum

Avcl (2017a ve 2017b), Ege ve Akdeniz bölgelerindeki kumullarda tespit ettiği en yaygın türler, bizim araştırma sahasında da benzer yoğunlukta görülmektedir. Akyol ve Gemici (2017), Batı Anadolu'da bulunan Balıkesir, İzmir, Aydın ve Muğla il sınırları içerisinde yer alan Kıyı Ege'deki kumul ekosistemlerinde ekolojik bir çalışma gerçekleştirmişlerdir. Çalışmada, bölgenin vejetasyon ekolojisi ve biyolojik çeşitliliğinin belirlenmiş ve buna bağı olarak mevcut ve potansiyel tehlikeler ile alınması gereken önlemler ortaya konulmuştur. Akyol ve Gemici (2017)'nin bulguları bazı farklılıklar göstermekle birlikte genel olarak bizim çalışma alanınkilerle benzerdir. Floristik ve ekolojk gözlemler sonucunda, kumul bitki 
çeşitliliğini ve yayılış alanlarını tehdit eden antropojenik faktörler belirlenmiştir.

Plaj düzenlemesi, kum çekimi ve kıyıya yakın alanlardaki tarımsal faaliyetler kumul bitkilerin yayılış alanlarına zarar vermektedir. Özellikle kum zambağı (Pancratium maritimum) gibi nadir bitkilerin halk tarafından soğanlarının toplanıyor olması türün popülasyonlarını tüketmiştir. Türkiye genelinde kıyı kesimlerinde yaygın olan bu bitkinin kıyı şeritlerinde maruz kaldığı tehditler, koruma ve çoğaltma önerileri le ilgili benzer çalışmalar da yapılmıştır (Gümüş ve Ellialtıŏlu 2006; Gülez ve ark. 2007; Gümüş 2015).

Gönen çayı kat ettiği güzergah boyunca sanayii ve evsel atıklarla kirlenerek deltaya ulaşmaktadır. Bu durum

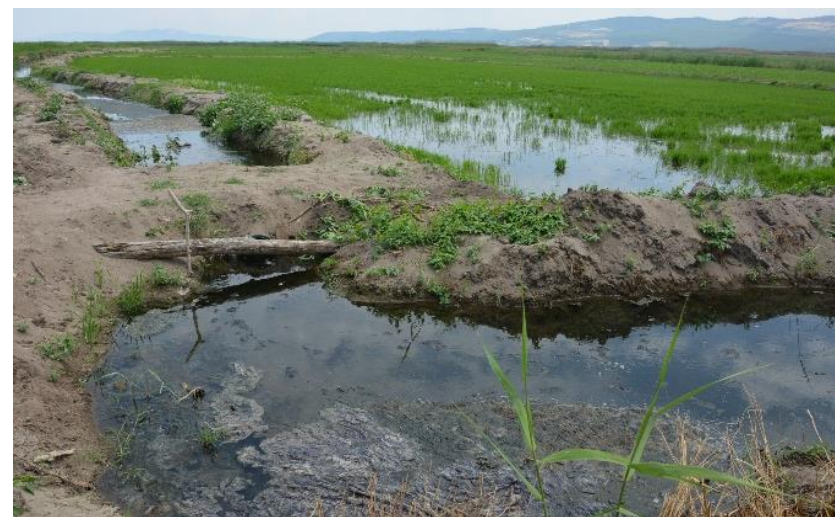

Şekil 5. Gönen Deltası kumul alan çevresinde gözlenen tarım ve kirlilik.

Yoğun alan kullanımları baskısı altındaki bu kıyı kumulları, ülkemizin floristik çeşitliliğinin bir parçasıdır ve korunması önemlidir. Bu amaçla; Kum zambağı gibi türlerin yaşam alanlarının olduğu kumul bölgeler koruma altına alınmalıdır (Şekil 4-G).

Gülez ve ark (2007) tarafından Bartın Muga'da kıyı alanları tasarımı için dört öneri proje sunulmuş. Alanda dağınık halde yayılış gösteren kum zambaklarını ( $P$. maritimum) doğal olarak koruyabilmek için alanın koruma alanı haline getirilmesi, bilgilendirici levhalarla birlikte etrafında gezinti yolu ve dinlenme sahası düşünülmüş. Gümüş ve Ellialtıoğlu (2006) ve Gümüş (2015), doğal yaşam alanlarının plaj olarak kullanılması, çiçeklerinin koparılması, soğanlarının toplanması ve bahçelerde süs bitkisi olarak kullanılması nedeniyle $P$. maritimum populasyonunun önemli derecede azaldığı ve neslinin kumul flora ve fauna için ortamı yaşanmaz hale getirmiştir. Kesif vejetasyonun olduğu alanlarda toprak kayıpları az iken, zemin örtüsünün olmadığı veya zayıf olduğu alanlarda kayıp daha fazladır.

Tahirova olarak adlandırılan Gönen Çayı Deltası, yoğun bir şekilde tarımsal faaliyetlerin yapıldığı bir alandır (Efe, 1993). Bu alanda başta pirinç olmak üzere buğday ve mısır tarımı da yapılmaktadır. Bu tarımsal kullanımın bilinçsiz bir şekilde yapılması delta alanındaki arazi kullanım değişimini de beraberinde getirmiştir (Efe, 1995; Özşahin ve Ekinci, 2012; 2013). Bu tarımsal alanlarda gübre ve tarımsal ilaç kullanımı sulak alanlara fazla miktarda besleyici element girdisine neden olmaktadır (Şekil 5).

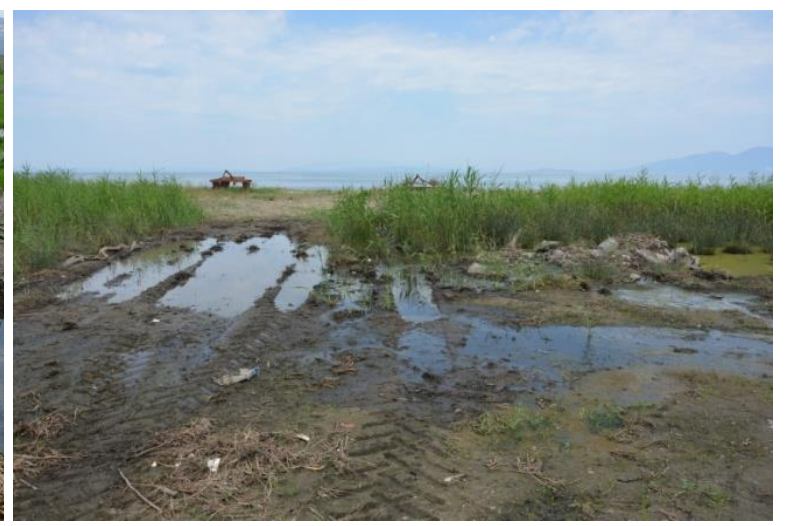

tehlike altında olduğu belirtmektedir. Türün koruma ve çoğaltılması için doğal alanlarının rehabilitasyon edilerek kumlu alanların bitkilendirilmesi ve türün hızlı çoğaltımında etkin bir in vitro protokolün geliştirilmesi gerekliliğini belirtmektedir.

Üst havzadan gelen kirlilik önlenmeli, sanayi tesislerinde arıtma sistemleri faaliyete geçirilmelidir. Deltadaki halihazırdaki arazi kullanımının tekrar gözden geçirilerek planlanması gerekmektedir. Yapılacak bütün uygulamaların sürdürülebilir bir şekilde planlanması insanın doğal ortamdan en yararlı bir şekilde faydalanmasına imkan sağlayacaktır. Tarımda bilinçsiz ilaç ve gübre kullanımının önüne geçilmelidir. Bölgedeki ekolojik sorunların temelinde denetimsizlik ve bilinçsizlik yer almaktadır. Bu nedenle, ekolojik planlama sürecinde bölge halkının da bilinçlendirilmesi önemlidir. 


\section{KAYNAKLAR}

Akyol Y, Gemici Y (2017) Kıyı Ege'nin (Gökova ve Edremit Körfezleri Arası) Vejetasyon Ekolojisi ve Biyolojik Çeşitliliğinin Ekolojik Yönetimi. Kastamonu Üniversitesi, Orman Fakültesi Dergisi, 17 (1): 116-123.

Avcı M (2017a) Türkiye'nin Kıyı Kumullarında Bitki Örtüsü, Yasal ve Bilimsel Boyutlarıyla: Kıyı (Ed. H. Turoğlu ve H. Yiğitbaşıoğlu), Jeomorfoloji Derneği Yayını No: 1, Anka matbaa, İstanbul: 63-92.

Avcı M (2017b) Türkiye'nin Kıyı Kumulları, Bitki Örtüsü ve Önemi. International Symposium on Geomorphology, 12-14 October 2017, Elazığ/Türkiye.

Avcı M, Avcı S, Akkurt S (2015) Coastal dune vegetation in Turkey: a geographical perspective. International Conference on the Mediterranean Coastal Environment MEDCOAST 2015, Varna, Bulgaristan, 6-10 Ekim 2015, vol.1: 397-405.

Davis P (1965-1985) Flora of Turkey and East Aegean Islands, Vol. 1-9, Edinburgh University Press, Edinburgh.

Davis P, Mill RR, Tan K (1988) Flora of Turkey and East Aegean Islands (Supplements I), Vol. 10, Edinburgh University Press, Edinburgh.

Efe R (1993) Marmara Denizi güneyinde Karabiga-Tahirova arasındaki kıyı kesiminin çevresel jeomorfolojisi. Türk Coğrafya Dergisi, 28:293-306.

Efe R (1995) Gönen ve dolaylarında gözlenen çevre sorunlarına coğrafi bir yaklaşım. Marmara Üniversitesi Sosyal Bilimler Enstitüsü Öneri Dergisi, 1(2): 97-101.

Erinç S (2001) Jeomorfoloji II (3.Basım) (Güncelleştirenler: A.Ertek ve C. Güneysu). Der Yay. No: 294, İstanbul.

Gülez S, Kaya LG, Dönmez Ş, Görmüş Çetinkale S, Koçan N. Mugada (2007) Kıyı Alanı Peyzaj Düzenlemesi Üzerine Bir Çalışma. ZKÜ Bartın Orman Fakültesi Dergisi, 9(12): 1-10.

Gümüş C, Ellialtıoğlu, Ş (2006). Kum zambağı (Pancratium maritimum)'nın doku kültürü ile çoğaltılma olanağı üzerinde bir çalışma. III. Ulusal Süs Bitkileri Kongresi 8-10 Kasım, İzmir, Bildiri Kitabı: 435-441.

Gümüş C. (2015) Kum zambağı (Pancratium maritimum L.) bitkisinde yapılan araştırmalar üzerinde bir inceleme. Derim, 32 (1): 89-105.
Güner A, Aslan S, Ekim T, Vural M, Babaç, MT (edlr.) (2012) Türkiye Bitkileri Listesi (Damarlı Bitkiler). Nezahat Gökyiğit Botanik Bahçesi ve Flora Araştırmaları Derneği Yayınları, İstanbul.

Güner A, Özhatay N, Ekım T, Başer KHC (2001) Flora of Turkey and East Aegean Islands (Supplements II), Vol. 11, Edinburgh University Press, Edinburgh.

IUCN (2019) The IUCN Red List of Threatened Species. Version. 20192. http://www.iucnredlist.org. Downloaded on 18 July 2019.

Öner HH, Akbin G (2010) Kapıdağ Yarımadası'nın Fitossoyolojik ve Fitoekolojik Yönden İncelenmesi. T.C. Çevre ve Orman Bak. Ege Ormancılık Ens. Müd. Teknik Bülten No:46.

Özmen H, Uysal i (2012) Çanakkale'de (Türkiye) Önemli Kumul ve Tuzcul Alanların Florası ve Ekolojisi. 21. Ulusal Biyoloji Kongresi, 03-07 Eylül 2012, Ege Üniversitesi, İzmir, Türkiye, ss. 669-670.

Özşahin E (2013) Gönen Çayı Deltası'nın Toprak Özelliklerinin Coğrafi Açıdan Değerlendirilmesi. Ekev Akademi Dergisi 17(57): 233-246.

Özşahin E, Ekinci D (2012) Marmara Denizi deltaları ve insan. Türkiye'nin Kıyı ve Deniz Alanları IX. Ulusal Kongresi 14-17 Kasım 2012, Antakya/Hatay, s.: 325-333.

Özşahin E, Ekinci D (2013) Marmara Denizi deltaları. III. Ulusal Jeomorfoloji Sempozyumu Bildiriler Kitabı (Editörler: Hüseyin Korkmaz, Atilla Karataş), s.: 26-37, Hatay: Color Ofset.

Roskov Y., Ower G., Orrell T., Nicolson D., Bailly N., Kirk P.M., Bourgoin T., DeWalt R.E., Decock W., Nieukerken E. van, Zarucchi J., Penev L., eds. (2019) Species 2000 \& ITIS Catalogue of Life, 2019 Annual Checklist. Digital resource at www.catalogueoflife.org/annualchecklist/2019. Species 2000: Naturalis, Leiden, the Netherlands. ISSN 2405-884X.

Strid A, Tan K. (eds.) (1991) Mountain flora of Greece. Vol. 2., Edinburgh University Press. Edinburgh, UK.

Tırıl A (2006) Sulak Alanlar, Peyzaj Mimarlar Odası Yayınları: 2006/2. ISBN 9944-89-141-X, 193 s. Ankara.

Tutin TG, Heywood VH, Burges NA, Valentine DH, Walters SM, Webb DA (1964-1980) Flora Europae, Vol: 1-5, Cambridge at Univ. Press, Cambridge.

Tümen G, Satıl F, Selvi S (2018) Manyas (Bandırma-Balıkesir) Kuş Cenneti ve Çevresinin Florası Üzerine Araştırmalar. International Symposium of Bandırma and Its Surroundings, p 397-415, Bandırma - Balıkesir / Turkey. 